\title{
EXPERIMENTAL STUDY ON MINIMUM QUANTITY LUBRICATION IN END MILLING OF AA6061-T6 USING TiAIN COATED CARBIDE TOOLS
}

\author{
M.S. Najiha and M.M. Rahman \\ Faculty of Mechanical Engineering \\ Unviersiti Malaysia Pahang, 26600 Pekan, Pahang, Malaysia \\ Email: mustafizur@ump.edu.my \\ Phone: +6094246239; Fax: +6094246222
}

\begin{abstract}
This paper presents an experimental investigation on the effects of output parameters during machining of aluminum alloy 6061-T6 using the minimum quantity lubrication (MQL) technique through end milling processes. In this study cutting speed, depth of cut, feed rate and MQL flow rate are selected as input parameters. Experiments are conducted using the central composite design method. Statistical models for process optimization are obtained using the response surface method. The objective of the study is to investigate and optimize the process parameters employing coated carbide cutting tools; coatings used are TiAlN. For the purpose of the study, surface roughness and material removal rate are selected as response variables. The results of the study show that the inserts coated with TiAlN perform very well, showing good machinability. According to the results of the study, MQL can easily be a suitable eco-friendly alternative to conventional flood cooling conditions. MQL proves to be more beneficial with the application of coated tools in end milling of aluminum alloys.
\end{abstract}

Keywords: Aluminum alloy 6061; minimum quantity lubrication; response surface method; TiAlN; TiN; material removal rate; surface roughness.

\section{INTRODUCTION}

Dry and near-dry machining operations are the key technology of environment-friendly sustainable manufacturing[1,2]. The minimum quantity lubrication technique has been serving as the most significant element in sustainable manufacturing since the last decade [3-5]. It aims at reducing the hazardous effects of coolants on the atmosphere and minimizing the resource consumption during a product's life cycle, which includes design, processing, production, packaging, transport, the use of the product and its disposal [6]. In operations that use traditional flood-cooling methods, coolant handling costs more than the fluid itself. For the wet machining of aluminum castings, for example, coolant-related costs are 10-20\% of total machining costs-roughly twice the costs of the cutting tools. But of this, only $25 \%$ is for the lubricant itself; the rest goes towards coolant supply maintenance $(42 \%)$ and operational energy costs (33\%). According to [7], the total costs of cutting fluids incurred during a machining process amount to about $7 \%$ to $17 \%$ of the total machining cost. Therefore the reduction in the amount of cutting fluids used during a machining process is a direct indicator of sustainable manufacturing [8]. MQL ensures the safety of the environment and the worker and is a cost-effective technique. The objective of MQL is to use the metalworking fluid in such a quantity that the final product, chip and machine remain a dry 
and safe environment. This amount is usually three to four orders of magnitude less than is normally used in wet machining The typical flow rate for MQL is about $50-500 \mathrm{ml} / \mathrm{hr}$ $[9,10]$. MQL machining has been acknowledged as an alternative to dry and wet machining on account of its eco-friendly distinctiveness. A considerable amount of research in the mentioned field has also established its potential application in many practical machining operations [11]. Machining with MQL has been widely applied in machining processes such as drilling [12-14], milling [1, 6, 15-21], turning [13, 22, 23], and MQL grinding [24-28].

With the rising global drive towards optimization, sustainable manufacturing is also inclining to manufacturing process optimization. For optimization, not only the use of a reduced quantity of metal cutting lubricants is important but also its optimized quantity. Optimum machining parameters can play a major role in the efficient consumption of machines and materials. In workshop practices the input machining parameters and variables are determined from handbooks and suppliers' data but optimum cutting data is essential for any machining operation for an effective, inexpensive process that is correlated with sustainable development. The objective of this study is to experimentally investigate the machining characteristics of aluminum alloy in end mill processes for flooded and MQL techniques using coated carbide tools.

\section{MATERIALS AND METHODS}

\section{Design of Experiments}

The machining variables considered in this research are spindle speed, feed rate, depth of cut and the minimum quantity lubricant flow rate. The central composite design approach of response surface methodology is used for the design of experiments in order to find the effects of parameters and combinations of parameters. Five levels of machining variables are selected for the MQL employing a TiAlN-coated carbide cutting tool. Design matrices are shown in Table 1, respectively.

Table 1. Design of experiment matrix for MQL conditions.

\begin{tabular}{lccccc}
\hline Factors & \multicolumn{5}{c}{ Levels } \\
\cline { 2 - 6 } & 1 & 2 & 3 & 4 & 5 \\
\hline Cutting speed $(\mathrm{rpm})$ & 5252 & 5300 & 5400 & 5500 & 5548 \\
Depth of cut $(\mathrm{mm})$ & 0.52 & 1.0 & 2.0 & 3.0 & 3.5 \\
Feed rate $\mathrm{f}_{\mathrm{z}}(\mathrm{mm} / \mathrm{min})$ & 288 & 318 & 379 & 440 & 4769 \\
MQL flow rate $(\mathrm{ml} / \mathrm{min} /$ nozzle) & 0.013 & 0.016 & 0.022 & 0.0275 & 0.030 \\
\hline
\end{tabular}

\section{Materials Properties}

This research is performed to determine the machinability of aluminum alloy 6061-T6 under minimum quantity lubrication. The study of the aluminum alloy workpiece was conducted with different types of cutting tool. To achieve acceptable tool wear, the speed of machining was set to the optimum. Tables 2 and 3 show the chemical, mechanical and thermal properties of AA6061-T6. It is observed that the thermal conductivity is high, which reduces the chance of adhesion during machining. The dimensions of the workpiece used in this study are $100 \times 100 \times 30 \mathrm{~mm}$. 
Table 2. Physical properties of AA6061-T6.

\begin{tabular}{llllll}
\hline Component & $\mathrm{Si}$ & $\mathrm{Mn}$ & $\mathrm{Mg}$ & $\mathrm{Ti}$ & $\mathrm{Zn}$ \\
\hline Weight $(\%)$ & $0.4-0.8$ & Max 0.15 & $0.8-1.2$ & $\operatorname{Max} 0.15$ & $\operatorname{Max} 0.25$ \\
\hline
\end{tabular}

Table 3. Mechanical and thermal properties of AA6061-T6.

\begin{tabular}{lcc}
\hline \multicolumn{1}{c}{ Properties } & Value & Unit \\
\hline Hardness, Brinell & 95 & - \\
Hardness, Knoop & 120 & - \\
Hardness, Rockwell A & 40 & - \\
Hardness, Rockwell B & 60 & - \\
Hardness, Vickers & 107 & - \\
Ultimate tensile strength & 310 & $\mathrm{MPa}$ \\
Tensile yield strength & 276 & $\mathrm{MPa}$ \\
Elongation at break & 12 & $\%$ \\
Elongation at break & 17 & $\%$ \\
Modulus of elasticity & 68.9 & $\mathrm{GPa}$ \\
Density & 2.7 & $\mathrm{~g} / \mathrm{cc}$ \\
Specific heat capacity & 0.896 & $\mathrm{~J} / \mathrm{g}-{ }^{\circ} \mathrm{C}$ \\
Thermal conductivity & 167 & $\mathrm{~W} / \mathrm{m}-\mathrm{K}$ \\
Melting point & 652 & ${ }^{\circ} \mathrm{C}$ \\
\hline
\end{tabular}

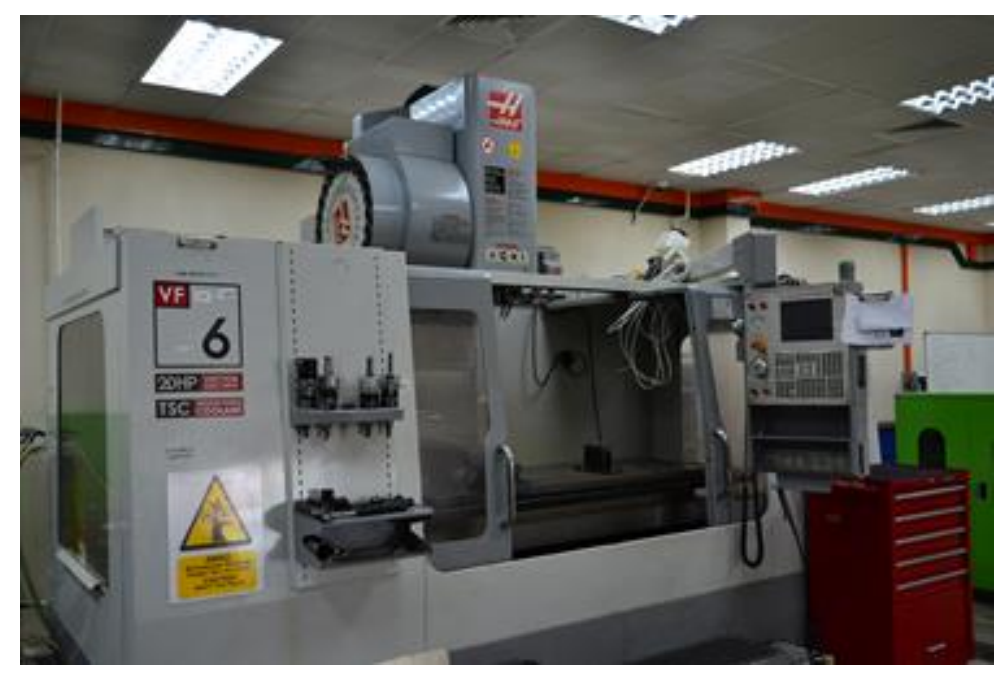

Figure 1. CNC end milling machine HAAS VF-6.

Figure 1 shows the CNC end milling machine HAAS VF-6 used to perform the machining with coated carbide inserts. The experiments conducted are based on the design of experiments mentioned in earlier sections. The minimum quantity lubricant used in this experiment is specially designed cutting oil UNIST 2210, which is a commercial non-toxic, vegetable oil-based cutting fluid. Three nozzles were fixed on the machine spindle and were set 26 degrees approximately from horizontal and 120 degrees apart so that they could cover the whole machining area. Figure 2 shows the MQL system with the coolant used and the nozzle configuration. 


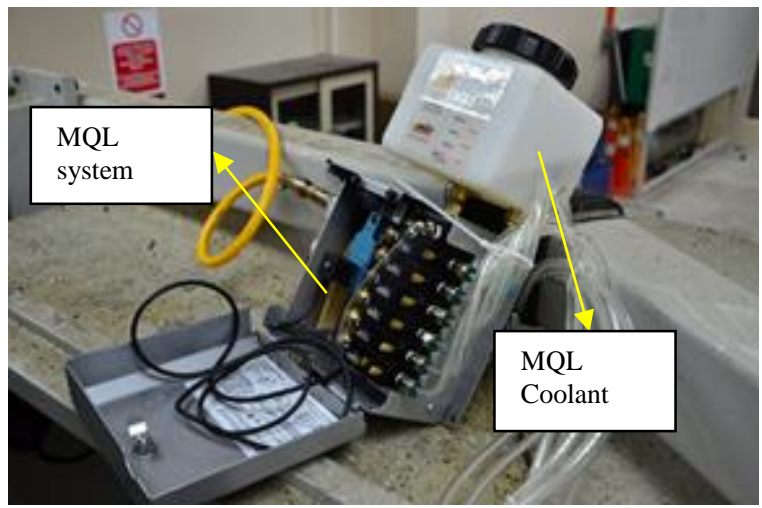

(a)

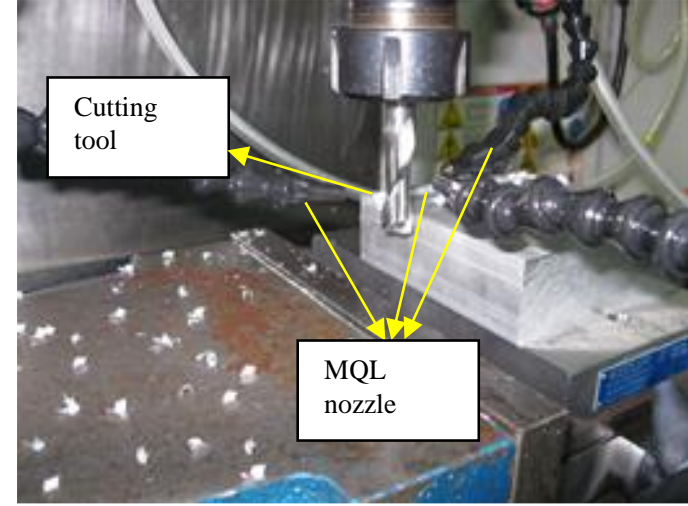

(b)

Figure 2. (a) MQL system and UNIST 2210 coolant; (b) arrangement of nozzles.

\section{Cutting Tool}

The cutting tools used for this experiment are coated carbide cutting tools with PVD coatings TiAlN. According to [29], coated carbide is suitable for machining because it is possible to employ the carbide- and nitride-based tool materials at cutting speeds that are so low that mechanical wear predominates. The cutting tool, tool holder and insert are shown in Figure 3 and the composition of the carbide inserts is signified in Table 4.

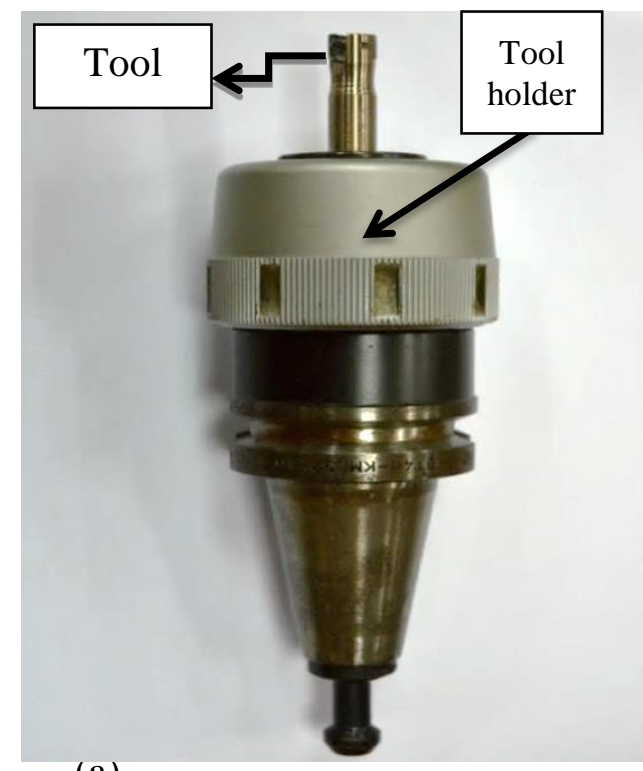

(a)

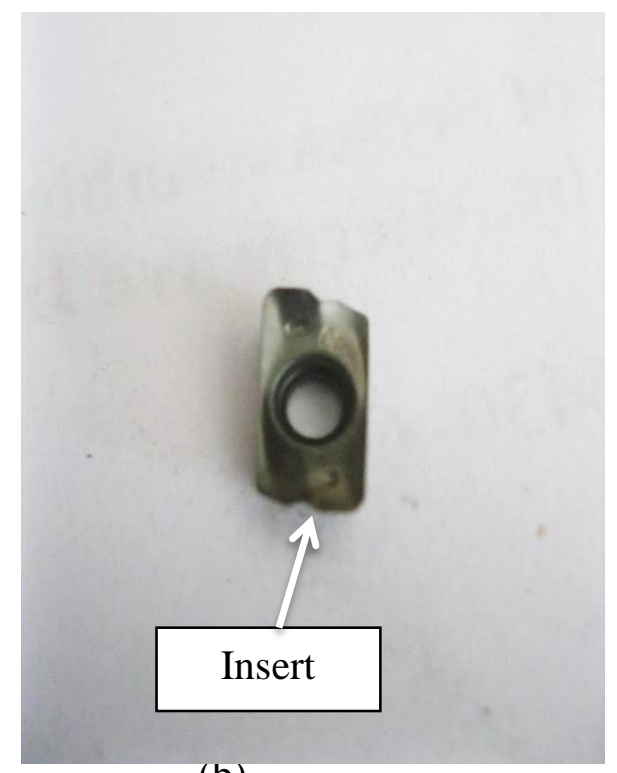

(b)

Figure 3. (a) Tool holder and cutting tool insert, (b) insert coated carbide tool.

Table 4. Composition of the coated carbide inserts.

\begin{tabular}{cccc}
\hline Type & Composition & $\begin{array}{c}\text { Hardness/coating } \\
\text { thickness }\end{array}$ & Grade \& make \\
\hline PVD & Co 12.5\%; mixed & HV 1380/4 $\mu \mathrm{m}$ & ISO-HC P40M40, \\
TiAlN- & $\begin{array}{c}\text { carbides 2.0\%; WC } \\
\text { balance }\end{array}$ & & XDKT070304SR-M50, \\
coated & CERATIZIT \\
\hline
\end{tabular}




\section{RESULTS AND DISCUSSION}

The measured values of surface roughness and material removal rate under flood cooling conditions are listed in Table 5. Corresponding regression coefficients for the surface roughness and material removal rate are given in Table 6 . The measured values of the surface roughness and material removal rate for the two coated inserts with minimum quantity lubrication are given in Table 7. Corresponding regression coefficients for the surface roughness and material removal rate are given in Table 8 . Response surface modeling has been used to develop the mathematical models in terms of the machining parameters by using the technique of minimum quantity lubrication. Second-order statistical models have been developed based on the surface roughness and material removal rate results.

Table 5. Measured values of average surface roughness and material removal rate under flood cooling machining conditions.

\begin{tabular}{ccccc}
\hline $\begin{array}{c}\text { Speed } \\
(\mathrm{RPM})\end{array}$ & $\begin{array}{c}\text { Feed rate } \\
(\mathrm{mm} / \mathrm{min})\end{array}$ & $\begin{array}{c}\text { Depth } \\
\text { of cut } \\
(\mathrm{mm})\end{array}$ & $\begin{array}{c}\text { Surface } \\
\text { roughness } \\
(\mu \mathrm{m})\end{array}$ & $\begin{array}{c}\text { MRR } \\
\left(\mathrm{mm}^{3} / \mathrm{min}\right)\end{array}$ \\
\hline 5400 & 379 & 0.37 & 0.311 & 1513.5 \\
5300 & 318 & 1.00 & 0.851 & 3422.8 \\
5300 & 440 & 1.00 & 0.396 & 4914.3 \\
5500 & 318 & 1.00 & 0.555 & 3522.0 \\
5500 & 440 & 1.00 & 0.277 & 4722.2 \\
5237 & 379 & 2.00 & 1.361 & 8371.5 \\
5400 & 279 & 2.00 & 0.773 & 6319.4 \\
5400 & 379 & 2.00 & 0.830 & 8868.1 \\
5400 & 379 & 2.00 & 0.775 & 8217.8 \\
5400 & 379 & 2.00 & 0.908 & 8454.2 \\
5400 & 379 & 2.00 & 0.867 & 8572.5 \\
5400 & 379 & 2.00 & 1.015 & 8406.9 \\
5400 & 379 & 2.00 & 0.913 & 8513.4 \\
5400 & 479 & 2.00 & 0.764 & 10803.2 \\
5563 & 379 & 2.00 & 1.223 & 8040.4 \\
5300 & 318 & 3.00 & 1.202 & 10188.9 \\
5300 & 440 & 3.00 & 1.161 & 14413.6 \\
5500 & 318 & 3.00 & 1.234 & 10913.1 \\
5500 & 440 & 3.00 & 1.538 & 13384.0 \\
5400 & 379 & 3.63 & 1.363 & 14780.1 \\
\hline
\end{tabular}

\section{Regression Modeling}

Table 8 shows that the model for surface roughness contains four squared terms, four linear terms and six interaction terms. The overall regression is significant with a $\mathrm{p}$ value $0.000<0.05$. All the four squared terms (Speed $x$ Speed; Feed rate $x$ Feed rate; Depth of cut $x$ Depth of cut and MQL flow rate $x$ MQL flow rate) show significance, i.e., the data obtained follow a curved trend. The linear term of the feed rate and the interaction between the feed rate and MQL flow rate also show significance. The quadratic model thus obtained, which shows a correlation of the surface roughness with 
input parameters, is given in Eq. (1). $\mathrm{R}^{2}$-value and lack-of-fit are $93.12 \%$ and 0.482 , respectively.

$$
\begin{gathered}
R_{a}=-234.691+0.092397 x_{1}-0.06537 x_{2}+0.182275 x_{3}-11.03 x_{4}+0.0000106 x_{1} x_{2} \\
+0.000132 x_{1} x_{3}-0.001645 x_{1} x_{4}-0.00048 x_{2} x_{3}-0.01234 x_{2} x_{4}+0.233333 x_{3} x_{4} \\
-8.98 \times 10^{-6} x_{1}^{2}+2.40 \times 10^{-5} x_{2}^{2}-0.18559 x_{3}^{2}+4.044785 x_{4}^{2}
\end{gathered}
$$

Table 6. Estimated regression coefficients for surface roughness and material removal rate under flood cooling machining conditions.

\begin{tabular}{lcccc}
\hline \multicolumn{1}{c}{ Term } & \multicolumn{2}{c}{ Surface roughness } & \multicolumn{2}{c}{ Material removal rate } \\
\hline Regression & Coefficient & p-value & Coefficient & p-value \\
Linear & - & 0.000 & - & 0.000 \\
Square & - & 0.001 & - & 0.044 \\
Interaction & - & 0.001 & - & 0.105 \\
Constant & - & 0.002 & - & 0.001 \\
Speed & 428.8845 & 0.000 & -477754 & 0.045 \\
Feed rate & -0.15276 & 0.000 & 160.5648 & 0.063 \\
Depth of cut & -0.05008 & 0.110 & 230.614 & 0.018 \\
Speed x Speed & -5.83747 & 0.007 & 2998.716 & 0.559 \\
Feed rate x Feed rate & 0.00001356 & 0.000 & -0.01341 & 0.087 \\
Depth of cut x Depth of cut & -0.00001631 & 0.034 & -0.00023 & 0.990 \\
Speed x Feed rate & -0.035 & 0.187 & -156.308 & 0.052 \\
Speed x Depth of cut & 0.0000107 & 0.067 & -0.04191 & 0.018 \\
Feed rate x Depth of cut & 0.00103 & 0.009 & -0.26562 & 0.776 \\
\hline & 0.002041 & 0.003 & 8.204713 & 0.000 \\
\hline
\end{tabular}

The material removal rates measured for MQL machining are listed in Table 8 along with the respective designs of experiment. Regression coefficients and analysis of variance is used to check the adequacy. The most significant terms are the quadratic term of depth of cut and the interaction of the feed rate with the depth of cut. The overall regression shows a significant $\mathrm{p}$-value $(0.000<0.05)$. The quadratic model for material removal rate is expressed as in Eq. (2). $\mathrm{R}^{2}$-value and lack-of-fit are $99.39 \%$ and 0.255 , respectively.

$$
\begin{gathered}
M R R=569187.1-221.819 x_{1}+146.9746 x_{2}+6218.277 x_{3}-564.521 x_{4} \\
-0.02217 x_{1} x_{2}-1.05522 x_{1} x_{3}+1.770059 x_{1} x_{4}+12.07621 x_{2} x_{3} \\
-10.1636 x_{2} x_{4}+389.7401 x_{3} x_{4}+0.021267 x_{1}^{2} \\
-0.02739 x_{2}^{2}-273.433 x_{3}^{2}-4723.67 x_{4}^{2}
\end{gathered}
$$


Table 7. Measured values of average surface roughness and material removal rate under minimum quantity lubrication (MQL) conditions

\begin{tabular}{|c|c|c|c|c|c|}
\hline $\begin{array}{l}\text { Speed } \\
(\mathrm{rpm})\end{array}$ & $\begin{array}{l}\text { Feed rate } \\
(\mathrm{mm} / \mathrm{min})\end{array}$ & $\begin{array}{l}\text { Depth of } \\
\text { cut } \\
\text { (mm) }\end{array}$ & $\begin{array}{l}\text { MQL flow rate } \\
(\mathrm{ml} / \mathrm{min})\end{array}$ & $\begin{array}{l}\text { Surface roughness } \\
(\mu \mathrm{m})\end{array}$ & $\begin{array}{c}\text { MRR } \\
\left(\mathrm{mm}^{3} / \mathrm{min}\right)\end{array}$ \\
\hline 5252 & 379 & 2.00 & 0.6525 & 0.562 & 9086.8 \\
\hline 5300 & 318 & 1.00 & 0.48 & 0.845 & 3523.0 \\
\hline 5300 & 318 & 1.00 & 0.825 & 0.486 & 3477.3 \\
\hline 5300 & 318 & 3.00 & 0.48 & 1.034 & 11042.1 \\
\hline 5300 & 318 & 3.00 & 0.825 & 0.875 & 10621.5 \\
\hline 5300 & 440 & 1.00 & 0.48 & 1.017 & 5456.6 \\
\hline 5300 & 440 & 1.00 & 0.825 & 0.516 & 5238.3 \\
\hline 5300 & 440 & 3.00 & 0.48 & 1.175 & 15642.2 \\
\hline 5300 & 440 & 3.00 & 0.825 & 0.563 & 15351.1 \\
\hline 5400 & 288 & 2.00 & 0.6525 & 1.033 & 6680.0 \\
\hline 5400 & 379 & 0.52 & 0.6525 & 0.212 & 2069.2 \\
\hline 5400 & 379 & 2.00 & 0.39 & 1.505 & 8460.2 \\
\hline 5400 & 379 & 2.00 & 0.6525 & 0.971 & 8773.5 \\
\hline 5400 & 379 & 2.00 & 0.6525 & 1.091 & 8710.8 \\
\hline 5400 & 379 & 2.00 & 0.9 & 0.803 & 8836.2 \\
\hline 5400 & 379 & 3.48 & 0.6525 & 0.745 & 14601.6 \\
\hline 5400 & 469 & 2.00 & 0.6525 & 1.132 & 10711.8 \\
\hline 5500 & 318 & 1.00 & 0.48 & 0.749 & 3680.7 \\
\hline 5500 & 318 & 1.00 & 0.825 & 0.623 & 3422.8 \\
\hline 5500 & 318 & 3.00 & 0.48 & 0.819 & 9885.3 \\
\hline 5500 & 318 & 3.00 & 0.825 & 1.098 & 10779.2 \\
\hline 5500 & 440 & 1.00 & 0.48 & 1.346 & 5092.79 \\
\hline 5500 & 440 & 1.00 & 0.825 & 0.606 & 4365.25 \\
\hline 5500 & 440 & 3.00 & 0.48 & 1.496 & 14756.75 \\
\hline 5500 & 440 & 3.00 & 0.825 & 0.906 & 14413.57 \\
\hline 5548 & 379 & 2.00 & 0.6525 & 0.816 & 9713.51 \\
\hline
\end{tabular}

Table 8. Estimated regression coefficients for surface roughness under minimum quantity lubrication (MQL) machining conditions.

\begin{tabular}{lcclc}
\hline Term & \multicolumn{2}{l}{ Surface roughness } & \multicolumn{2}{l}{ Material removal rate } \\
\hline & Coefficient & p-value & Coefficient & p-value \\
\hline Regression & - & 0.000 & - & 0.000 \\
Linear & - & 0.072 & - & 0.074 \\
Square & - & 0.001 & - & 0.044 \\
Interaction & - & 0.018 & - & 0.011 \\
Constant & -234.691 & 0.069 & 569187.1 & 0.178 \\
Speed & 0.092397 & 0.054 & -221.819 & 0.153 \\
Feed Rate & -0.06537 & 0.043 & 146.9746 & 0.072 \\
Depth of cut & 0.182275 & 0.916 & 6218.277 & 0.068 \\
MQL flow rate & -11.03 & 0.288 & -564.521 & 0.374 \\
Speed x Speed & -8.98 E-06 & 0.045 & 0.021267 & 0.134 \\
Feed rate x Feed rate & 2.40 E-05 & 0.046 & -0.02739 & 0.748 \\
Depth of cut x Depth of cut & -0.18559 & 0.001 & -273.433 & 0.007 \\
MQL flow rate x MQL flow rate & 4.044785 & 0.012 & -4723.67 & 0.592 \\
Speed x Depth of cut & 1.06 E-05 & 0.060 & -0.02217 & 0.079 \\
Speed x Feed rate & 0.000132 & 0.676 & -1.05522 & 0.116 \\
Speed x MQL flow rate & -0.001645 & 0.377 & 1.770059 & 0.375 \\
Feed rate x Depth of cut & -0.00048 & 0.363 & 12.07621 & 0.001 \\
Depth of cut x MQL flow rate & 0.233333 & 0.218 & 389.7401 & 0.115 \\
\hline
\end{tabular}



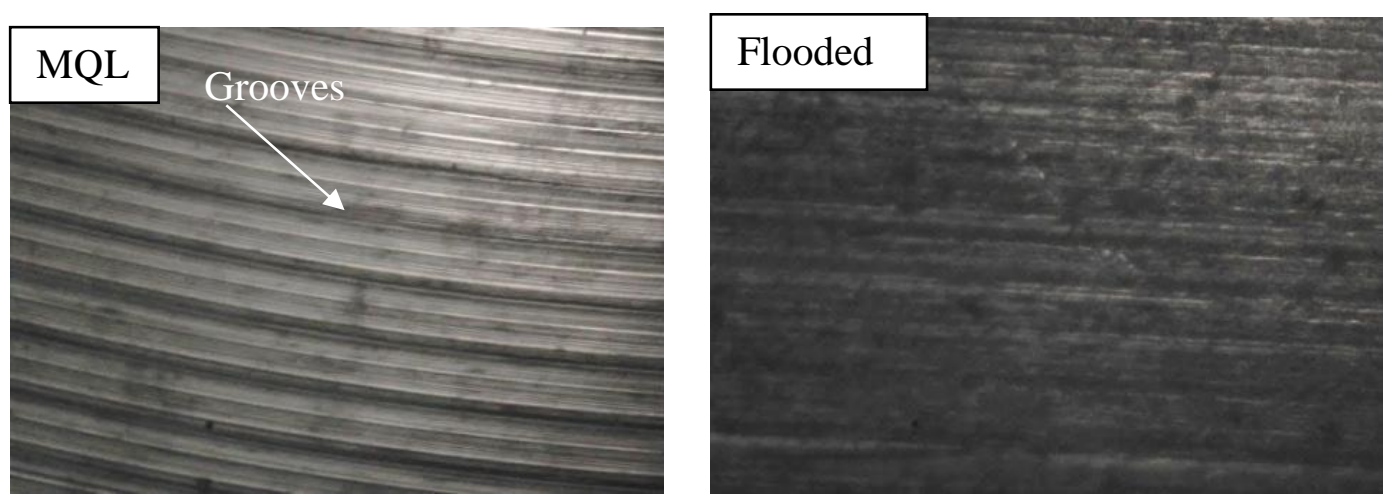

(a) Cutting speed
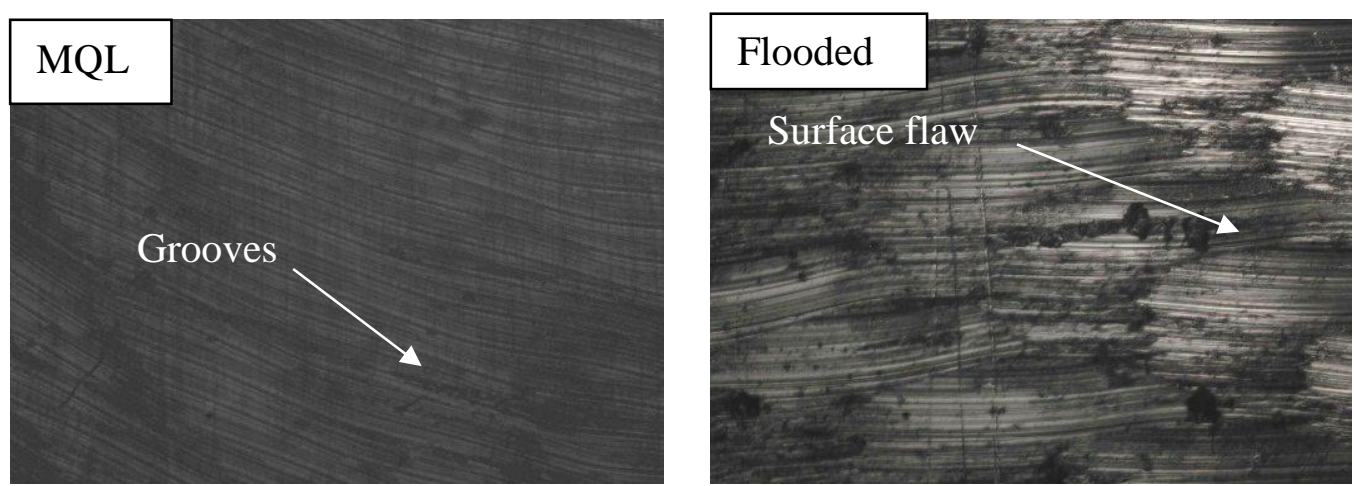

(b) Feed rate

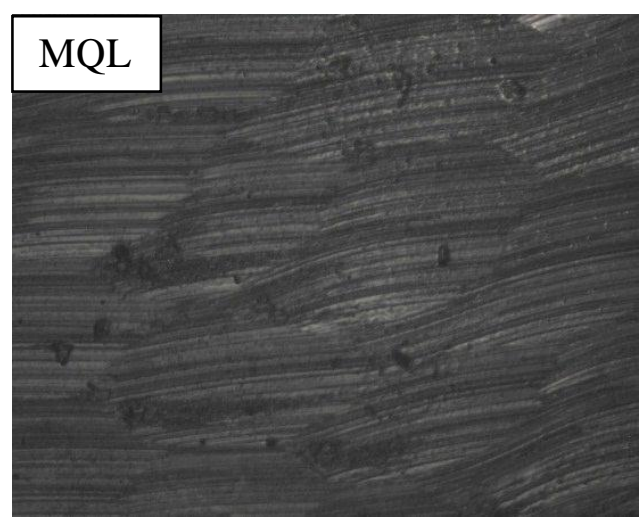

(a) MQL

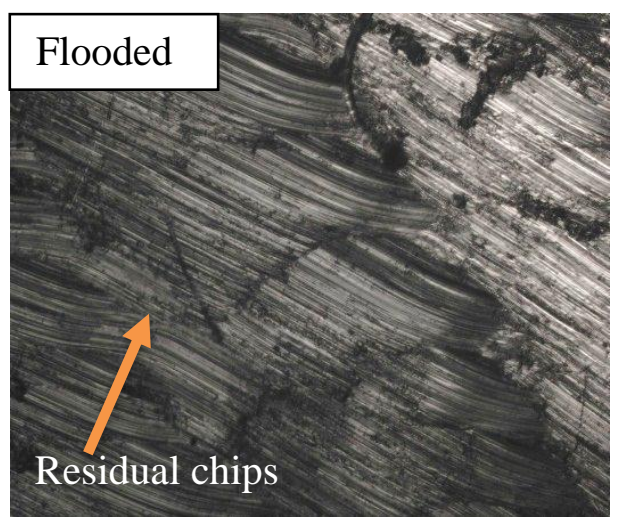

(b) flooded

(c) Depth of cut

Figure 4. Image of surface roughness for maximum cutting speed, feed rate and depth of cut for MQL and flooded conditions

Figure 4(a) shows the surface condition of the machined aluminum alloy $6061 \mathrm{~T} 6$ taken using an optical microscope. The flooded machined workpiece has a wavier pattern, composed of more valleys and a coarser surface finish compared to the minimum quantity lubrication surface finish. Comparing MQL and flooded conditions in terms of cutting speed, both are associated with each other's factor but MQL has a 
better result, where the points in the diagram can be seen to be the lowest in surface roughness at every speed. This means that the surface roughness value is superior in MQL compared to flooded machining. The images also show that with flooded machining the surface roughness increases when the cutting speed increases, while the surface roughness of MQL decreases when the cutting speed increases. Figure 4(b) shows the comparison of MQL and flooded conditions in terms of feed rate, where both are associated with each other's factor but MQL has a better result, where the points in the diagram can be seen to be the lowest in surface roughness compared to the flooded surface roughness. This means that the surface roughness value is superior in MQL, while the flooded condition shows the highest surface roughness value. The flooded machined workpiece has a wavier pattern, composed of more valleys and has a coarser surface finish compared to the minimum quantity lubrication surface finish. The MQL surface finish is smoother and has minimal swirl marks compared to the flooded machining. Figure 4(c) shows comparison of the surface finish of aluminum alloy $6061 \mathrm{~T} 6$ in terms of depth of cut by using MQL machining and flooded machining, with images taken using the optical microscope. The flooded machined surface finish has a wavier pattern, composed of more valleys compared to the minimum quantity lubrication surface finish. The MQL surface finish is smoother compared to the flooded machining. As the depth of cut increases, the surface finishes of aluminum alloy become rougher. The MQL has a uniform swirled and bright buffed finish, while flooded machining produced a large-pattern matte finish.

\section{Comparison of Predicted Response Variables}

Figure 5 shows the comparison of predicted surface roughness in flood cooling, MQL (oil) and MQL (nanofluid) conditions with TiAlN-coated inserts. In Figure 5(a) variations of surface roughness are plotted with respect to cutting speed at a constant feed rate of $379 \mathrm{~mm} / \mathrm{min}$ and depth of cut of $1.0 \mathrm{~mm}$. Surface roughness in MQL (oil) machining gradually decreases with increasing flow rates. The surface roughness values predicted by the models for MQL machining are lower than those predicted for the flood cooling models. Only for the mid-range of cutting speed, i.e. 5350 to $5450 \mathrm{rpm}$, the surface roughness for flood cooling shows some improvements on the surface roughness furnished from an MQL flow rate of $0.48 \mathrm{ml} / \mathrm{min}$, while for all the other flow rates, the surface roughness is always lower than the flood cooling predicted values. The variation of surface roughness for flood cooling follows an exact inverse pattern with MQL machining. As depth of cut increases to $2.0 \mathrm{~mm}$ (Figure 5(b)), the predicted values of the response in flood cooling are higher than those predicted from the MQL models. For a depth of cut of $3.0 \mathrm{~mm}$ and feed rate kept at $379 \mathrm{~mm} / \mathrm{min}$ (Figure 5(c)), the surface roughness predicted from the MQL models is lower than the flood cooling values for all values of the MQL flow rate.

Variation of surface roughness with feed rate at constant depth of cut and speed shows a mixed effect (Figure 6). For a depth of cut of $1.0 \mathrm{~mm}$ and MQL flow rate of $0.48 \mathrm{ml} / \mathrm{min}$ the surface roughness predicted by the MQL machining models is higher than those predicted from the models for flood cooling (Figure 6(a)). As the MQL flow rate increases to $0.65 \mathrm{ml} / \mathrm{min}$ and $0.83 \mathrm{ml} / \mathrm{min}$, the surface finish for MQL machining is superior. When the depth of cut is increased to $2.0 \mathrm{~mm}$ (Figure 6(b)), the predicted surface roughness increases in all cases, including flood cooling and MQL conditions. With depth of cut at $2.0 \mathrm{~mm}$ and MQL flow rates at $0.65 \mathrm{ml} / \mathrm{min}$ and $0.83 \mathrm{ml} / \mathrm{min}$ the predicted response is lower than the response from the flood cooling models. When the 
depth of cut is further increased to $3.0 \mathrm{~mm}$ (Figure 6(c)), the surface roughness values from flood cooling are much higher.

Surface roughness vs speed, depth of cut $=1.0 \mathrm{~mm}$, feed rate $=379 \mathrm{~mm} / \mathrm{min}$

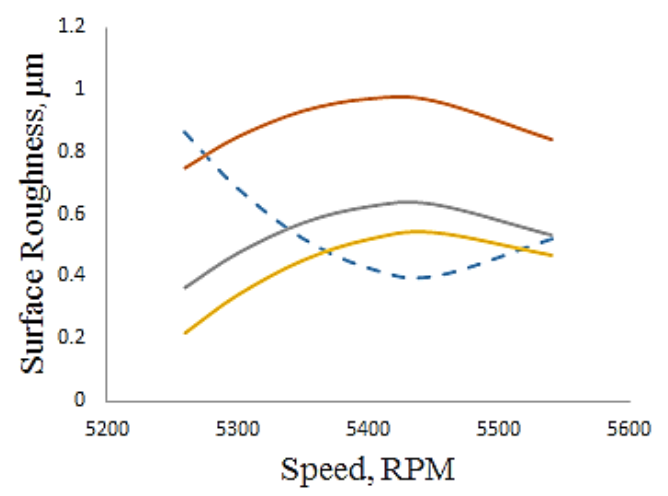

(a)

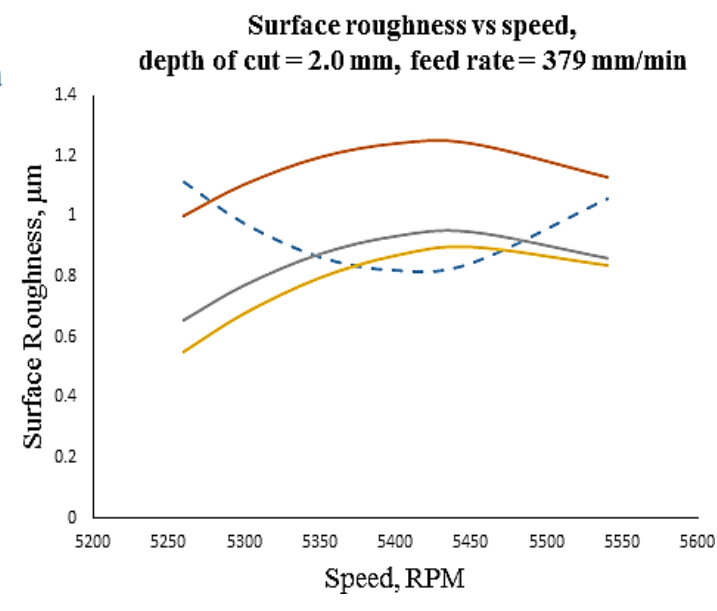

(b)

Surface roughness vs speed, depth of cut $=3.0 \mathrm{~mm}$, feed rate $=379 \mathrm{~mm} / \mathrm{min}$

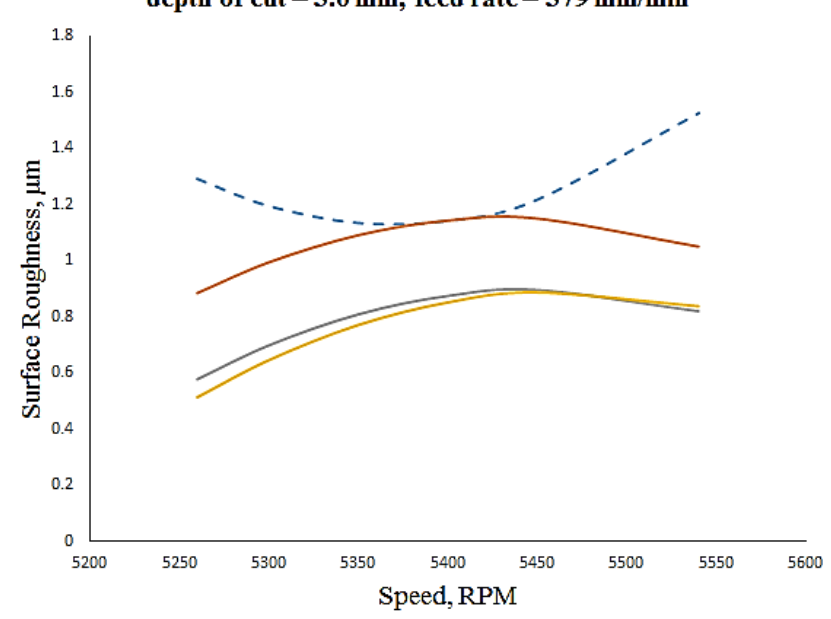

(c)

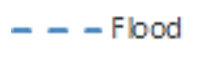

Figure 5. Comparison of model-predicted surface roughness against cutting speed at constant feed rate and depth of cut for TiAlN-coated insert

With increasing depth of cut, the variation of predicted surface roughness in flood cooling and MQL machining conditions is plotted in Figure 7. For a feed rate of $318 \mathrm{~mm} / \mathrm{min}$ at constant speed, the flood cooling predicted values are higher. The surface roughness predictions show an increasing trend with increasing depth of cut. As the feed rate increases to $379 \mathrm{~mm} / \mathrm{min}$ (Figure 7(b)), the surface roughness with MQL machining is higher. At a feed rate of $440 \mathrm{~mm} / \mathrm{min}$ (Figure 7(c)), the surface finishes predicted are comparable in both environments, but the MQL flow rate at this feed rate yields a superior surface finish with increasing depth of cut. 


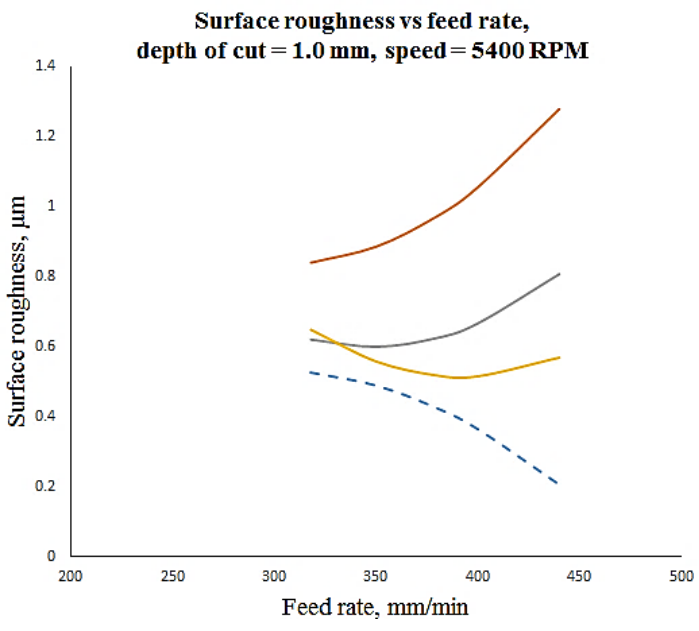

(a)

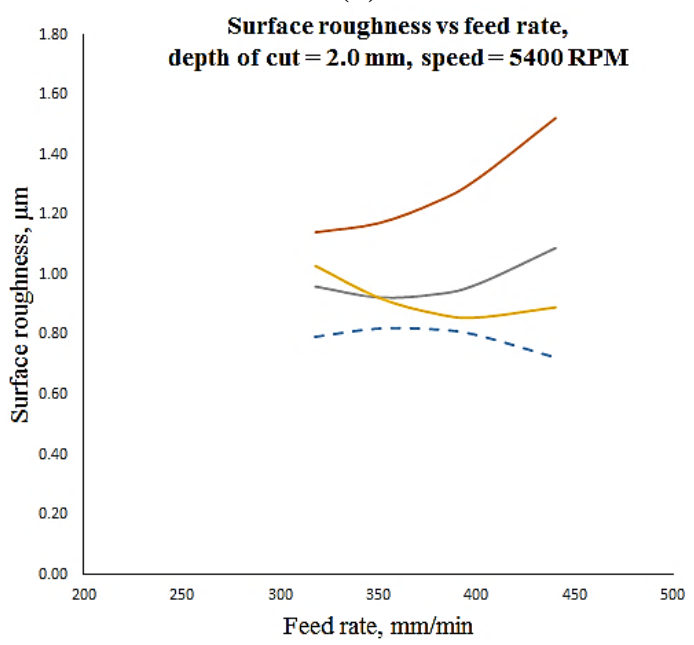

(b)

Surface roughness vs feed rate,

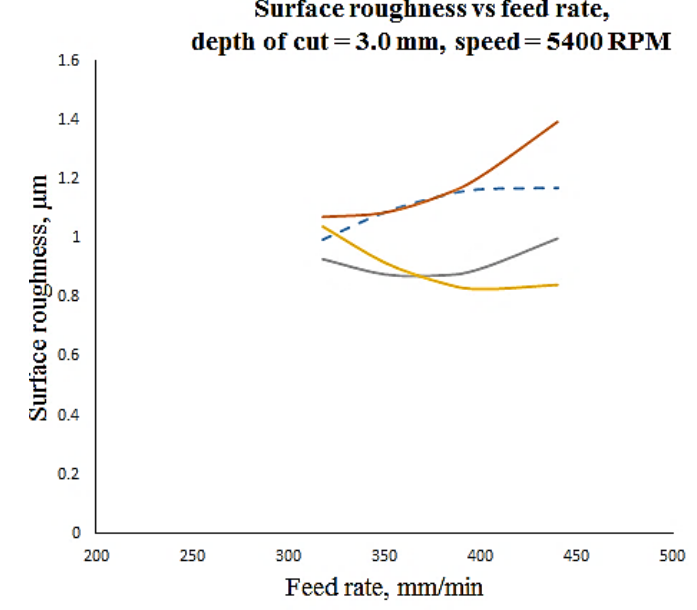

(c)

Figure 6. Comparison of model-predicted surface roughness against feed rate at constant speed and depth of cut. 


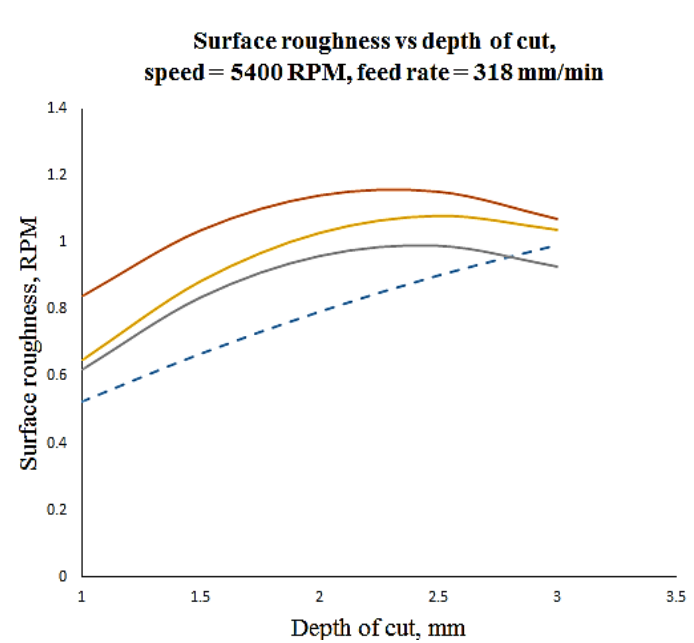

(a)

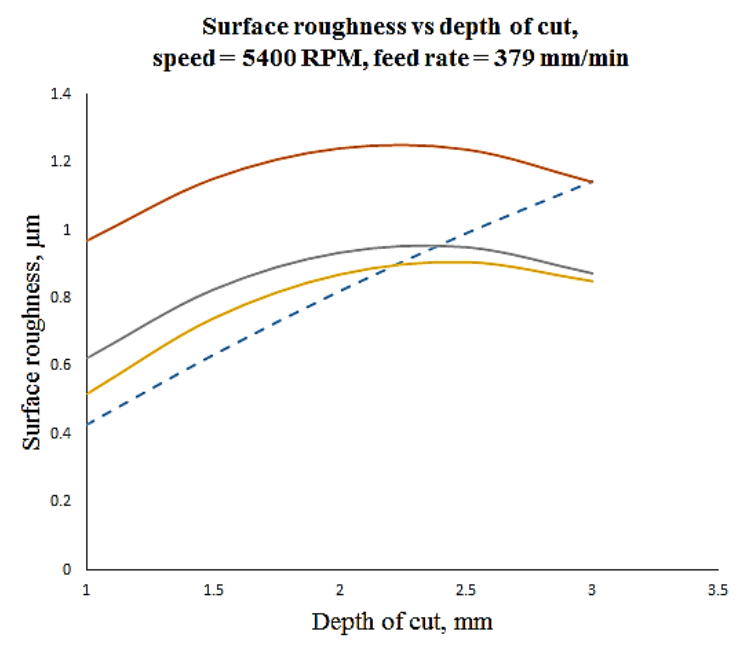

(b)

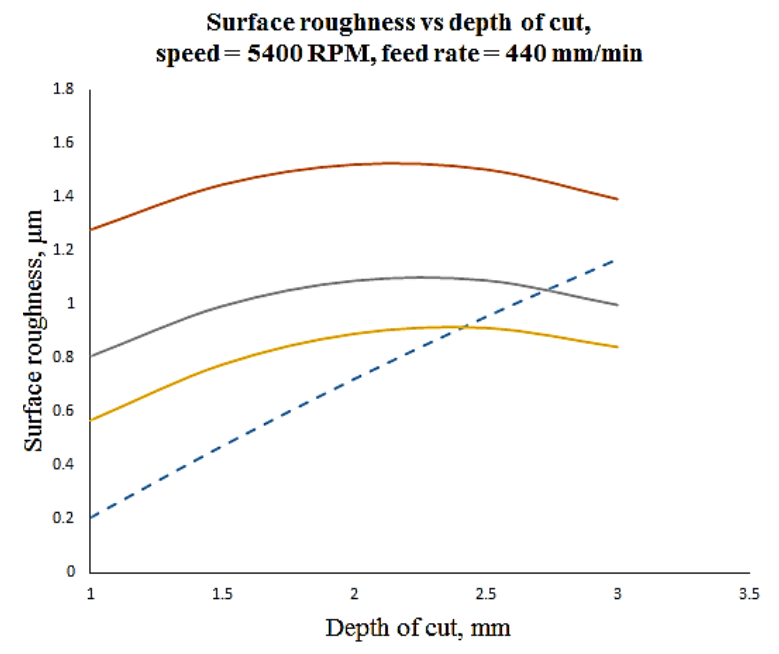

(c)

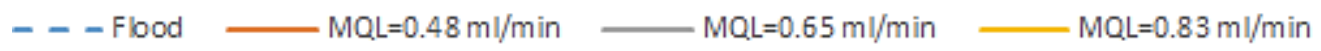

Figure 7. Comparison of model-predicted surface roughness against depth of cut at constant speed and feed rate.

\section{CONCLUSIONS}

Machining parameters such as feed rate, spindle speed, depth of cut and MQL flow rate (in the case of MQL machining) play a significant role in the machinability and productivity of a process. In this study, the effects of machining parameters on surface quality and material removal rate are investigated in flood cooling and MQL machining conditions. Second-order regression models are developed and ANOVA is applied for analyzing the experimental data. The results show that surface roughness is considerably affected by depth of cut, followed by feed rate and spindle speed. Surface roughness increases with depth of cut and spindle speed, while it decreases with increasing feed rate. The material removal rate is significantly affected by the interaction of the feed rate and depth of cut, with depth of cut being the most effective parameter on material rate. The results of machining with flood cooling are compared with those from MQL machining and it is concluded that the MQL machining results in 
very comparable results in terms of surface roughness and material removal rate, although at most of the design points the MQL surface roughness values are much lower than those from flood machining.

\section{ACKNOWLEDGEMENTS}

The authors would like to acknowledgements Ministry of Education Malaysia and Universiti Malaysia Pahang for providing laboratory facilities and financial support under project no. RDU110110 and Postgraduate Grant Scheme no. GRS140310.

\section{REFERENCES}

[1] Najiha MS, Rahman MM, Kamal M, Yusoff AR, Kadirgama K. Minimum quantity lubricant flow analysis in end milling processes: A computational fluid dynamics approach. Journal of Mechanical Engineering and Sciences. 2012;3:340-5.

[2] Che Ghani SAB, Cheng K, Minton T. Back chip temperature in environmentally conscious turning with conventional and internally cooled cutting tools. Journal of Mechanical Engineering and Sciences. 2013;4:356-72.

[3] Najiha MS, Rahman MM, Yusoff AR, Kadirgama K. Investigation of flow behavior in minimum quantity lubrication nozzle for end milling processes. International Journal of Automotive and Mechanical Engineering. 2012;6:76876.

[4] Najiha MS, Rahman MM, Yusoff AR. Modeling of the end milling process for aluminum alloy AA6061t6 using HSS tool. International Journal of Automotive and Mechanical Engineering. 2013;8:1140-50.

[5] Najiha MS, Rahman MM. A Computational Fluid Dynamics Analysis of Single and Three Nozzles Minimum Quantity Lubricant Flow for Milling. International Journal of Automotive and Mechanical Engineering. 2014;10:1891-900.

[6] Rahman M, Kumar AS, Salam MU. Experimental evaluation on the effect of minimal quantities of lubricant in milling. International Journal of Machine Tools and Manufacture. 2002;42:539-47.

[7] Weinert K, Inasaki I, Sutherland JW, Wakabayashi T. Dry machining and minimum quantity lubrication. CIRP Annals - Manufacturing Technology. 2004;53:511-37.

[8] Marksberry PW, Jawahir IS. A comprehensive tool-wear/tool-life performance model in the evaluation of NDM (near dry machining) for sustainable manufacturing. . International Journal of Machine Tools and Manufacture. 2008;48:878-86.

[9] Thakur DG, Ramamoorthy B, Vijayaraghavan L. Optimization of minimum quantity lubrication parameters in high speed turning of superalloy Inconel 718 for sustainable development. World Academy of Science, Engineering and Technology. 2009;54():224-6.

[10] Dhar NR, Kamruzzaman M, Ahmed M. Effect of minimum quantity lubrication (MQL) on tool wear and surface roughness in turning AISI-4340 steel. Journal of Materials Processing Technology. 2006;172.

[11] Tan XC, Liu F, Coo HJ, Zhang H. A decision making frame work model of cutting fluid selection for green manufacturing and a case study. nternational Journal of Machine Tools and Manufacture. 2002;129:467-70. 
[12] Filipovic A, Stephenson DA. Minimum quantity lubrication applications in automotive power-train machining. Machining Science and Technology. 2006;10:3-22.

[13] Davim JP, Sreejith PS, Silva J. Turning of brasses using minimum quantity of lubricant and flooded lubricant conditions. Materials and Manufacturing Processes. 2007;22:45-50.

[14] Heinemann R, Hinduja S, Barrow G, Petuelli G. Effect of MQL on the tool life of small twist drills in deep-hole drilling. International Journal of Machine Tools and Manufacture. 2006;46:1-6.

[15] Rahman M, Kumar AS, Salam MU. Evaluation of minimal quantities of lubricant in end milling. International Journal of Advanced Manufacturing Technology. 2001;18:235-41.

[16] Lacalle LNLD, Angulo C, Lamikiz A, Sanchez JA. Experimental and numerical investigation of the effect of spray cutting fluids in high speed milling. Journal of Materials Processing Technology. 2006;172:11-5.

[17] Su YL, Liu TH, Su CT, Yao SH, Kao WH, Cheng KW. Wear of CrC-coated carbide tools in dry machining. Journal of Materials Processing Technology. 2006;171:108-17.

[18] Liao YS, Lin HM. Mechanism of minimum quantity lubrication in high speed milling of hardened steel. International Journal of Machine Tools and Manufacture. 2007;47:1660-6.

[19] Kadirgama K, Rahman MM, Ismail AR, Bakar RA. Finite element analysis of HASTELLOY C-22HS in end milling. Journal of Mechanical Engineering and Sciences. 2011;1:37-46.

[20] Puvanesan M, Rahman MM, Najiha MS, Kadirgama K. Experimental investigation of minimum quantity lubrication on tool wear in aluminum alloy 6061-t6 using different cutting tools. International Journal of Automotive and Mechanical Engineering. 2014;9:1538-49.

[21] Razak NH, Rahman MM, Kadirgama K. Experimental study on surface integrity in end milling of hastelloy C-2000 superalloy. International Journal of Automotive and Mechanical Engineering. 2014;9:1578-87.

[22] Wakabayashi T, Sato H, Inasaki I. Turning using extremely small amounts of cutting fluids. JSME International Journal. 1998;41:143-8.

[23] Kamata Y, Obikawa T. High speed MQL finish-turning of Inconel 718 with different coated tools. Journalof Material Processing Technology. 2007;192:2816.

[24] Baheti U, Guo C, Malkin S. Environmentally conscious cooling and lubrication for grinding. In: Performance PotISoIMT, editor.1998. p. 643-54.

[25] Hafenbraedl D, Malkin S. Environmentally-conscious minimum quantity lubrication (MQL) for internal cylindrical grinding. Transactions of North American Manufacturing Research Institution/Society of Manufacturing Engineers (NAMRI/SME); 2000: 149-54.

[26] Silva LR, Bianchi EC, Catai RE, Fusse RY, Franca TV. Study on the behavior of the minimum quantity lubricant - MQL technique under different lubricating and cooling conditions when grinding ABNT 4340 steel. Journal of the Brazilian Society of Mechanical Sciences and Engineering 2005;27:192-9.

[27] Rahman MM, Kadirgama K, Ab Aziz AS. Artificial neural network modeling of grinding of ductile cast iron using water based $\mathrm{SiO} 2$ nanocoolant. International Journal of Automotive and Mechanical Engineering. 2014;9:1649-61. 
[28] Yusoff AR, Mohamed Suffian MRZ, Taib MY. Literature review of optimization technique for chatter suppression in machining. Journal of Mechanical Engineering and Sciences. 2011;1:47-61.

[29] Ghani JA, Choudhury IA, Masjuki HH. Wear mechanism of TiN coated carbide and uncoated Cermets tools at high cutting speed applications. Journal of Materials Processing Technology. 2004;153-154:1067-73. 